\title{
BACANTES: LA PERVERSIDAD DE UIN RITUAL TRASTOCADO
}

\author{
LUISINA ABRach \\ Universidad Nacional del Comahue - CONICET \\ luisina.abrach@gmail.com
}

\begin{abstract}
Este artículo propone dar cuenta de los elementos rituales que atraviesan Bacantes de Eurípides. Se hará especial referencia a la estructura hímnica del prólogo, y a los elementos que subvierten el sacrificio de Penteo y lo superponen con el ámbito de la caza. De esta manera, se establece que el prólogo consiste en un himno dedicado a Dioniso que es ejecutado por el mismo dios, y que la particularidad de este artificio anticipa el rol doble que va a ocupar Baco a la vez que el carácter impío de los hechos que se van a narrar. En consecuencia, la tragedia parecería poner en escena la representación de un culto a modo de ejemplo o, si se quiere, la representación de un castigo ejemplar, pero en todo caso, evocando la propia práctica teatral.
\end{abstract}

Bacantes / Ritual / Estructura hímnica / Sacrificio / Dioniso

\section{BACCHAE: THE PERVERSITY OF A SUBVERT RITUAL}

This article proposes to account for the ritual elements across the Bacchae of Euripides. A special reference will be made to the prologue hymnic structure and to the elements that subvert the sacrifice of Penteo and that overlap it with the hunt range. In this way, it is established that the prologue consists of a hymn dedicated to Dionysus, executed by the same god, that the particularity of this artifice anticipates the double role that Bacchus will occupy, and the impious quality of the facts that will be narrated. Consequently, the tragedy would seem to bring to light the representation of a cult as an example or the representation of an exemplary punishment, but in any case, evoking the own theatrical practice.

Bacchae / Ritual / Hymnic structure / Sacrifice / Dioniso 


\section{U}

na extensa cantidad de testimonios griegos antiguos fueron parte de alguna celebración cívico-religiosa cuando no constituyeron uno de sus elementos principales; así, el estudio de la literatura griega por la crítica especializada no puede dejar de considerar la importancia del elemento ritual que la atraviesa. Esta relación tan íntima del pueblo griego con la religión traspasa con distinta intensidad la forma y el contenido de toda obra transmitida desde la Grecia antigua. En esta línea se puede abordar Bacantes, obra póstuma de Eurípides, la cual narra la historia de cómo Dioniso castigó a Tebas por no reconocer su naturaleza divina, así como también la instauración de su culto en la polis. Estas intenciones del dios, en conjunto y en tensión, son las que estructuran la totalidad de la obra tanto formalmente como en el desarrollo de las acciones, como se intentará demostrar en esta ocasión.

Así, este trabajo se propone dar cuenta de los elementos rituales que atraviesan la tragedia considerando que la muerte de Penteo puede leerse como un sacrificio mal ejecutado, a la vez que funciona como un proceso de purificación previo a la iniciación de Tebas en los cultos dionisíacos. Bajo esta misma línea interpretativa, SEAFORD (1981 y 1987) sostuvo que

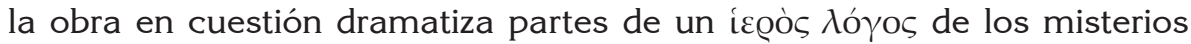
dionisíacos -así como el Himno Homérico a Deméter parece derivar de un

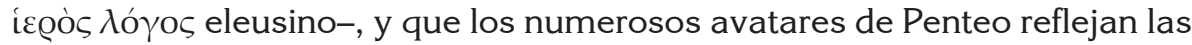
experiencias de aquel que va a ser iniciado. Esta lectura resulta significativa para comprender la complejidad de los diferentes elementos cultuales que están operando a la vez en la tragedia analizada, ya que se estarían superponiendo los distintos momentos rituales: la purificación, la iniciación a la vez que la celebración (perversa) del culto.

El ámbito de poder de Dioniso en el siglo V en Atenas era amplio, complejo y contradictorio, como el de casi ningún otro dios del panteón. Estaba asociado no sólo a la locura y al descontrol ritualizado, a las mujeres y al mundo natural fuera de la polis, a Apolo y a Delfos, al vino y los festivales, sino también al teatro en sí mismo dado que todas las obras eran representadas en honor a él. IRIARTE (1996), al indagar el porqué de la identificación de Dioniso con el teatro, remarca el carácter de alteridad y ambigüedad constitutivo del dios, y cómo este coincide con la problematización constante que pone en escena el mismo teatro; incluso, fuentes tempranas demuestran que los griegos siempre veneraron a Dioniso de una manera teatral, ya sea mediante máscaras, disfraces o música y danza.

Sin embargo, el tema dionisíaco estuvo ausente de todas las representaciones trágicas anteriores a la analizada en esta ocasión (NÁpol, 2012). Eurípides escribió Bacantes cuando sus contemporáneos recién estaban cobrando conciencia de la naturaleza teatral del dios (FOLEY, 1985:206), lo cual resulta de particular importancia considerando el modo en el que 
se desenvuelven las acciones en esta tragedia, ya que Dioniso actúa como profeta de sí mismo, a la vez que ocupa el rol de dramaturgo al tramar el desarrollo de la muerte de Penteo ${ }^{1}$. En este sentido, en Bacantes se despliega una serie muy amplia de relatos y representaciones acerca del efecto que genera la contemplación del espectáculo, de manera tal que también se espeja el efecto que genera la representación teatral en el espectador (NÁpoli, 2012). Así, se puede ver cómo esta tragedia resulta una puesta en escena, reflexión y complejización no sólo de un mito en particular sino también de prácticas culturales y religiosas.

\section{Sobre el carácter himnódico del prólogo}

No se puede dejar de observar que una obra que habla sobre la impiedad, comienza con un himno dedicado a Dioniso que a la vez es pronunciado por el mismo dios. Es de común acuerdo que la estructura de los himnos consiste en tres partes, en general, una introducción en la que se invoca al dios (invocatio), una sección media en la que se desarrolla un mito y/o se describe los atributos de la deidad invocada (pars epica para AuSFELD, 1903 y argument para BREMER, 1981), y una conclusión en la que se efectúan todos o algunos de estos elementos: saludo, pedido y referencia a otra canción (precatio) (Cf. JANKO, 1981:15). Esta tripartición característica de los Himnos homéricos (CÀssola, 1997) se extiende a otros himnos de la antigüedad y la antigüedad tardía (Cf. ABRITTA, 2012:121; MoRAnd, 2001:40; DE Hoz, 1998:54). La estructura hímnica puede ser identificada con cierta facilidad en el prólogo de Bacantes, a pesar de tener ciertas variaciones que están en correspondencia con el ritual trastocado del que forma parte. Además, no debemos olvidar que el prólogo sigue cumpliendo con la función contextualizadora que le corresponde.

La invocatio se encuentra al comienzo de los poemas y tiene como función atraer la atención de la divinidad a la que está dirigido el himno. En esta sección puede aparecer la primera persona marcando al suplicante. También suele estar presente el nombre del dios como primera palabra del primer verso -aunque existen muchas excepciones. La sección se da por terminada cuando aparece una cláusula relativa que tiene como término anafórico al dios invocado. Así se presentan los primeros versos de esta tragedia:

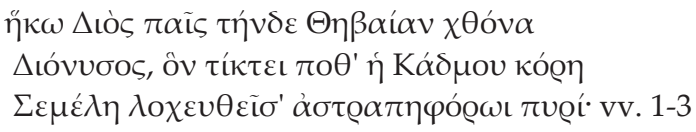

1 Cf. NÁPOL (2010) para un análisis detallado sobre la reflexión que plantea Bacantes acerca del fenómeno teatral a partir del desarrollo del tópico del teatro dentro del teatro. 
Llego a esta tierra de los Tebanos, hijo de Zeus,

Dioniso, al que aquí concibió la hija de Cadmo,

Sémele, habiéndolo dado a luz por el fuego nacido del rayo. vv. 1-32

Encontramos la primera persona, el nombre del dios y la cláusula de relativo. A través del pasaje de primera a tercera persona, el dios se desdobla en suplicante y divinidad invocada ${ }^{3}$. No debe extrañar este artificio literario, puesto que esta dualidad anticipa y espeja al dios disfrazado de profeta de sí mismo que se desarrollará a lo largo de toda la obra (Nápolı, 2010: 3). La finalidad de cualquier himno consiste en interpelar a la divinidad para que conceda la demanda solicitada al final de la plegaria, o que se una a la celebración en la que se está ejecutando la misma. En el caso analizado, se superpone la invocatio con la finalidad del himno, puesto que el dios suplicado ya se hizo presente $\left(\eta \kappa \kappa \omega^{4}\right)$. El desdoblamiento mencionado tiene que ver con el rol que le ha tocado en suerte a Dioniso, ya que él mismo va recorriendo ciudades instaurando su propio culto (vv. 13-22). Por lo tanto, no resulta extraño que el primer himno entonado en honor a Baco en Tebas sea por el mismo dios.

Podemos identificar la sección intermedia del himno a partir del pronombre relativo, ya que normalmente la cláusula es el elemento de unión entre la introducción y la segunda parte, al punto de que JANKO (1981:10) puede definir la introducción como "el contenido hasta el primer pronombre relativo". En esta sección encontramos el relato del nacimiento de Dioniso (vv. 26-31), tipo de contenido que es muy frecuente considerando que sucede en 13 de 20 de los llamados Himnos homéricos "míticos" 5 . Asimismo, es común que en las plegarias se le recuerde al dios los dones ya otorgados en función de convencerlo de que reitere los favores (Cf. Safo Fr. 1 vv. 5-24). También, suelen especificarse los ámbitos de poder del dios y la supremacía de éste -como un equivalente prolijo y adornado de "vos que podés..." (BURKERT, 1985)-. En el himno que Dioniso se canta a sí mismo, encontramos que se rememora la ausencia del recuerdo del dios en las ple-

2 Todas las traducciones del griego al español son de la autora.

3 Este rol doble es consecuente con la superposición de Dioniso en tanto actor de profeta de sí mismo, y dramaturgo de las acciones que se desarrollan en la obra. Es decir, no sólo actúa de un personaje distinto a sí mismo sino que entreteje y manipula las acciones y personajes, estableciendo una dualidad a su vez con el propio Eurípides. Sobre la reduplicación general en la obra cf. SEgAL, 1997: 27-54.

4 Ese verbo es frecuentemente utilizado para describir visitas sobrenaturales (DodDs, 1963: 62).

5 JaNKo (1981) distingue los Himnos homéricos según las características de la sección media en atributivos y en míticos. Los primeros se caracterizan por desarrollar los atributos del dios, utilizando en general el tiempo presente, y los segundos desarrollan un mito que narra algún suceso del dios interpelado en tiempo pretérito. 
garias y libaciones (vv. 45-46), a la vez que se relata el ultraje que recibió Sémele por parte de su familia (vv. 26-31); de esta manera queda establecida la calidad de las ofrendas que Tebas presentó al dios en cuestión, y en consecuencia la calidad de los dones que serán recibidos por la ciudad.

Considerando la relación de reciprocidad intrínseca a la religión griega entre el devoto y la deidad, entendemos que la $\mu \alpha v i ́ \alpha$ instaurada en Tebas tiene que ver con la relación de ida y vuelta propia entre el suplicante y el

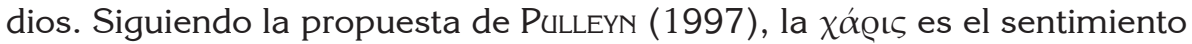
sostén de las plegarias que no son simplemente una ecuación matemática de doy-para-recibir, sino que implican un continuum de reciprocidad con la divinidad. Así, frente al ultraje, frente al olvido cultual, Dioniso se hace presente mostrando su poderío por la negativa, sosteniendo la reciprocidad correspondiente al instaurar la locura entre las mujeres tebanas.

En este punto del análisis, queda por agregar la conciencia que los devotos tenían sobre la dualidad intrínseca al poderío de todo dios. Como explica BURKERT, en la religión griega no existe el diablo pero todo dios tiene su lado terrible y peligroso (1985:188). Es frecuente encontrar, en el corpus hímnico, que se les solicite a los dioses que se acerquen atempe-

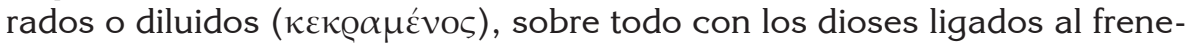
sí y la ruptura de los límites como Pan o Dioniso. Pero a todo el panteón

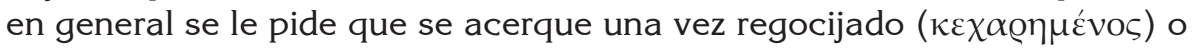
con ánimo benévolo ( $\varepsilon \dot{u} \mu \varepsilon v \eta ́ s)$, después de que haya recibido la ofrenda consistente en un himno, en el humo de los sahumerios, en las libaciones o cualquier otro gesto ${ }^{6}$.

Así, el hombre griego vive con la esperanza del favor recíproco aunque nunca puede contar con ello de modo seguro. También existe cierta libertad en la dirección contraria ya que, así como no hay obediencia al dios, tampoco hay órdenes; pero lo fundamental es que los dioses siempre son y permanecen como superiores (BURKERT, 1985:189). El accionar de Dioniso resulta completamente natural para los códigos religiosos vigentes, ya que está en estrecha correspondencia con los honores recibidos por parte de la ciudad; incluso el no haber aceptado el culto ofrendado por Cadmo, quien también es finalmente castigado. Esta actitud se explica porque ante todo un dios puede escuchar o no la plegaria de un devoto. Así, en el proto-himno en honor a Dioniso, en vez de cantarse los medios en los que se ha regocijado o atemperado al dios, se exponen las ofensas con máscaras de ofrendas.

Ahora bien, volviendo específicamente al análisis estructural del prólogo, la última sección de los himnos en general, llámese precatio o deman-

6 Sobre el estudio de las ofrendas en la Antigua Grecia cf. PATERA, 2012. 
da, suele estar introducida por la conjunción adversativa característica del género $\dot{\alpha} \lambda \lambda \dot{\alpha}$, que, en este caso, encontramos en el v. $55^{7}$ :

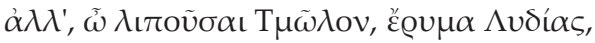

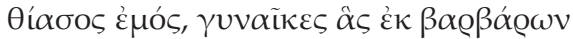

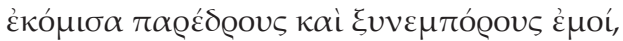

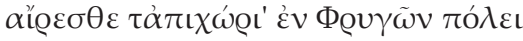

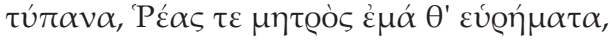

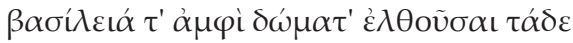

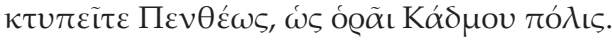
$\dot{\varepsilon} \gamma \dot{\omega} \delta \dot{\varepsilon} \beta \dot{\alpha} \kappa \chi \alpha \iota \varsigma, \grave{\varepsilon} \varsigma \mathrm{K} \mathrm{\iota} \theta \alpha \iota \tilde{\omega} v о \varsigma \pi \tau v \chi \dot{\alpha} \varsigma$

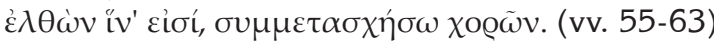

Pero, oh las que habiendo abandonado el Tmolo, defensa de Lidia, mi tíaso, mujeres, las que recogí de los bárbaros, como compañeras y allegadas mías, blandid el tamboril en la ciudad de los frigios, invención mía y de la madre Rea, y rodeando las casas reales de Penteo hacerlas resonar, para que vea la ciudad de Cadmo. y yo yendo con las Bacantes hacia la cima del Citerón, donde están, me uniré en sus danzas. (vv. 55-63)

La conjunción adversativa característica está seguida por una invocación (v. 55), verbos en modo imperativo (v. 58, v. 62) y una proposición adverbial final (v. 61). Incluso, si somos flexibles, habría una referencia a una próxima canción o performance si consideramos que el dios se unirá con las Bacantes en sus danzas en la cima del Citerón (vv. 63-64). Ahora bien, la objeción que se podría realizar sería que quienes están siendo interpeladas son las Bacantes y no Dioniso; no obstante, como se estableció más arriba, Dioniso se desdobla en suplicante y suplicado, por lo cual, en este caso, estaría actuando en tanto sujeto suplicante. Además, debemos recordar que es un himno corrupto, justamente porque antecede a un sacrificio en honor a Dioniso por parte de una ciudad no iniciada en sus cultos; y como es ampliamente reconocido, la distinción entre lo sagrado y lo profano reside en la exigencia de rigurosidad en la ejecución de los pasos rituales (BURKERT, 1985:77).

7 El prólogo de Hipólito, en boca de Afrodita, también presenta esta conjunción adversativa al final del mismo (v. 52). No obstante, el contexto que lo acompaña no tiene rasgos hímnicos. 


\section{Sobre aquello que pervierte el ritual}

La falta de exigencia en la ejecución de los pasos rituales de Bacantes es fundamental para comprender el contexto y la condición de los personajes al desarrollarse la tragedia. Con este objetivo se observan los siguientes versos del prólogo:

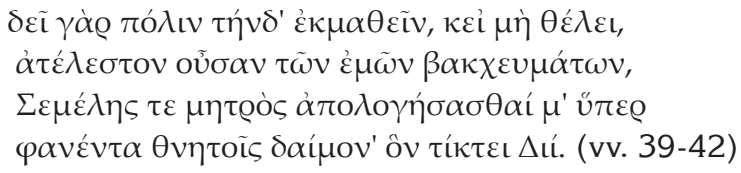

Pues hace falta que la ciudad aprenda, aunque no quiera, siendo no iniciada en mis fiestas báquicas, y que yo hable en defensa de mi madre, Sémele, manifestándome a los mortales como un dios que concibió para Zeus. (vv. 39-42)

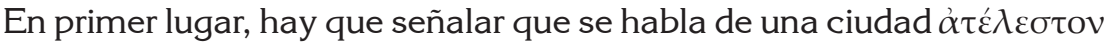
oũo $\alpha v$. El tiempo presente del participio establece la condición actual de la ciudad, lo cual resulta profundamente significativo considerando que se sabe que las mujeres ya están bajo los efectos del dios (vv. 32-36) ${ }^{8}$. En segundo lugar, es interesante observar la elección del lexema $\beta \alpha ́ \alpha \chi \varepsilon v \mu \alpha$, ya que se trata de un sustantivo neutro deverbal cuya terminación en $\mu \alpha \tau-$ indica el resultado de la acción (Cf. TORRES, 2015: 80), en este caso del verbo $\beta \alpha \kappa \chi \varepsilon v ́ \omega$. De esta manera, el sustantivo en cuestión establece implícitamente el proceso que significa honrar al dios, en otras palabras, los pasos rituales que conlleva. En consecuencia, se observa una ciudad que no ha cumplimentado el proceso que implica todo ritual, pero cuyas mujeres, no obstante, ya han comenzado los bailes dionisíacos.

En tercer lugar, es necesario subrayar el carácter forzado del aprendizaje de la ciudad. El dios opta por un compuesto de $\mu \alpha v \theta \alpha ́ v \omega$ que re-

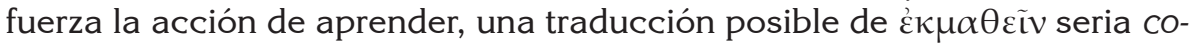
nocer en detalle, conocer en profundidad; así, el dios pauta la calidad de la acción requerida y evoca el escarmiento correspondiente. Asimismo, el carácter forzado del aprendizaje queda explicitado con la concesiva que

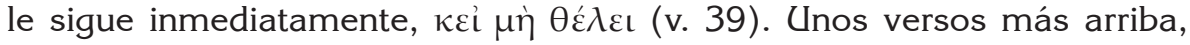

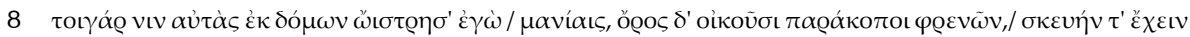

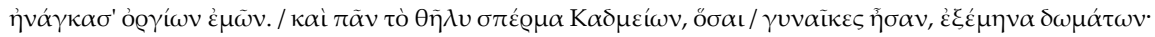
Pues por eso, yo las excité fuera de sus casas/ con locuras, y habitan los montes frenéticas de pensamientos, / y las obligué a llevar el estilo de mis cultos secretos/ y a toda la estirpe femenina de los Cadmeos, cuantas/ mujeres habían las saqué locas de sus casa. (vv. 32-36) 
dando cuenta de lo que sucedía con las mujeres de Tebas, Dioniso expli-

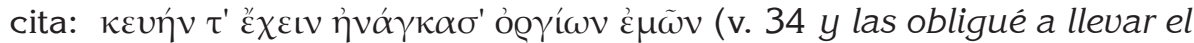
hábito de mis cultos secretos). Nótese el matiz de obligación otorgado por la elección del verbo $\dot{\alpha} v \alpha \gamma \kappa \alpha ́ \zeta \omega$. Las mujeres están cumpliendo el ritual sin una elección consciente.

RodríGuez CidRE (2014) ha señalado el proceso de animalización que opera en la construcción de los personajes femeninos en Bacantes, mecanismo frecuente por cuanto permite dar cuenta de la alteridad radical con la que la polis concibe a lo femenino. En este caso, dado que en la tragedia analizada el recurso de animalización aparece de forma hiperbólica en una sobreexplotación que recae sobre la mayoría de los personajes (RodRíGuEz CiDRE, 2014:20; SEgAL, 1997: 27 y ss.; Thumiger, 2007:122 y ss.). Este trabajo considera que el ámbito extendido de lo salvaje pone de manifiesto la falta de discernimiento entre lo profano y lo sagrado; así, la falta de conciencia de las mujeres tebanas a la hora de rendirle culto al dios está en concordancia con la irracionalidad intrínseca a la bestia. Es decir, se trata de sujetos que, al no haber reconocido el origen divino de Dioniso, han confundido los límites entre los dioses, los humanos y los animales (FolEY, 1985); de modo que, si los tebanos se acercan a lo sagrado, lo hacen necesariamente en forma híbrida. Esta confusión encarna con claridad cuando las mujeres amamantan cervatillos y cachorros de lobo (vv. 699-704) en un locus amoenus donde con un solo golpe sobre la tierra manan fuentes de agua y elixir (vv. 705-710). Los límites entre dioses, hombres y bestias colapsan especialmente cuando sacrifican-cazan a Penteo, momento que será analizado con mayor detalle más adelante.

Volviendo a los versos arriba citados, lo fundamental es que las mujeres están llevando los hábitos de Baco sin estar iniciadas, lo que se explici-

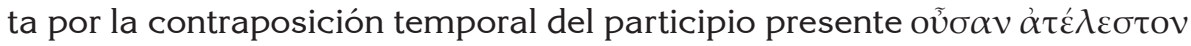
del v. 40, referido a la situación de la polis, y el verbo en aoristo நjvó $\gamma \kappa \alpha \sigma \alpha$ del v. 34. Esto es más que pertinente puesto que caracteriza en profundidad el contexto y los agentes que la tragedia va a desarrollar. Así, se puede decir hasta ahora que se trata de una ciudad no iniciada cuyas mujeres fueron forzadas a celebrar los cultos de Baco sin ser conscientes de ello, y

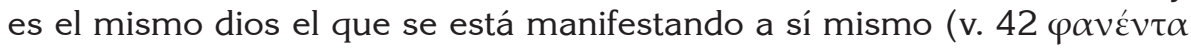

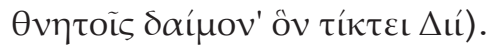

\section{Sobre la caza y el sacrificio ritual}

Es interesante observar que en la Grecia antigua existía un frenesí colectivo $(\mu \alpha v i ́ \alpha)$, cultual e institucionalizado. En general, el objetivo tanto en el mito como en la realidad es hacer que la locura se vuelva cordura 
de nuevo, un proceso que requiere purificación y un sacerdote purificador (BURKERT, 1985:76). En palabras de DOUGLAS,

Ritual recognizes the potency of disorder. In the disorder of the mind, in dreams, faints and frenzies, ritual expects to find powers and truth which cannot be reached by conscious effort. Energy to command and special powers of healing come to those who can abandon rational control for a time. (1966:114)

Estos procesos forman parte de toda relación con lo sagrado y de todas las formas de iniciación, pero también se emplean en situaciones de crisis: de locura, de enfermedad, de culpa (BuRKERT, 1985:77). Aquí se podría decir que Tebas está atravesando un proceso de purificación, ya sea porque está saldando la culpa por no rendirle los honores correspondientes a Dioniso, ya sea porque la polis se está iniciando en el culto al dios ${ }^{9}$; de todas maneras, para alcanzar ese poder sanador es necesaria una pérdida de control racional momentánea, como explica Douglas más arriba. También se puede sostener que están sucediendo las dos cosas a la vez, lo cual explicaría la superposición de la situación de sacrificio con la situación de caza que sucede al final del relato. Es decir, Penteo, quien aparece por primera vez en escena volviendo de cazar y está dispuesto a apresar a las ménades e incluso al mismo dios (vv. 335 ss.), resulta engañado y dispuesto como víctima sacrificial para finalmente ser desmembrado como una presa salvaje (vv. 1125 ss.). Así, Penteo, el vocero de Tebas del ultraje a Dioniso, al no reconocer el límite divino, él mismo se confunde con una

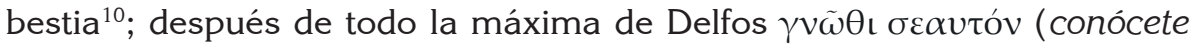
a ti mismo), no significa otra cosa que el hombre se reconozca a sí mismo en su distancia al dios, que reconozca su condición mortal (BURKERT, 1985:148). Ésta es la v̌ßıı que caracteriza a Penteo en tanto héroe trágico y, por extensión, a toda la polis tebana.

La tragedia se presentaba ante un público que mayoritariamente manejaba con naturalidad el código de los sacrificios ${ }^{11}$, por lo cual podemos suponer que la performance de Bacantes daba ciertas pistas que le anticipaban al espectador el destino funesto de Penteo al tiempo que se iba desarrollando la tragedia. Como se explicó más arriba, la exigencia de pureza en cualquier ritual establece la frontera que separa lo sagrado de lo profano

9 A esta última explicación podemos agregar la observación de SEGAL sobre la escena de Tiresias y Cadmo (vv. 170-214) como una manifestación temprana de iniciación dionisíaca (1997:194-6).

10 Para un análisis de la animalización de Penteo cf. Rodríguez Cidre (2012).

11 Se conjetura que el público habría estado compuesto mayoritariamente por ciudadanos pero también por extranjeros que estarían de paso por la polis. Cf. Brioso SánCHEz (2003). 
y se manifiesta en la rigurosidad de los pasos rituales del culto (BURKERT, 1985: 77). Así, el sacrificio de Penteo cumple con algunas de las reglas para la correcta ejecución de un sacrificio. En primer lugar, la elección especial de la víctima, que no es otro que el rey de Tebas. Además, sabemos que Penteo acude al monte por su propia voluntad habiendo sido convencido por Dioniso-profeta ${ }^{12}$. En paralelo, los animales antes de ser sacrificados eran inducidos mediante algún estímulo a asentir con la cabeza demostrando su consentimiento de ser sacrificado. Asimismo, los animales recibían un adornamiento especial tal como Penteo recibe los cuidados necesarios en relación a su vestimenta; y eran guiados hacia el altar sacrificial por el sacerdote como Baco guía a Penteo en este caso. Por otra parte, está el grito de la mujer y la implicación de todos los participantes en la muerte sacrificial (FOLEY, 1985: 210).

Estas marcas funcionan para indicar y subrayar la condición de Penteo como víctima. No obstante, en tanto ser humano de sexo masculino ${ }^{13}$, no satisface los requisitos mínimos para ocupar completamente ese lugar. Además, se cometen otras irregularidades en la ejecución, tales como la ausencia de un objeto filoso en la ceremonia o que no es un sacerdote hombre quien la realiza. Incluso, en rigor, su muerte no sucede en un contexto sacrificial, sino que deviene en presa ya que una vez que Dioniso lo conduce al lugar que debería funcionar como altar y lo delata frente a las ménades, se quiebra la situación de sacrificio y cobra fuerza el campo simbólico de la caza. Es también cuando la animalización de Penteo se refuerza (RodríGuez CiDRE, 2010), que este pierde absolutamente su vinculación con lo humano para pasar a ser un felino desmembrado.

Ahora bien, cabe preguntarse cómo puede ser interpretada esta transición y superposición entre caza y sacrificio. SEgal (1997) observa que la violencia contenida del sacrificio se transforma en la violencia desenfrenada de la caza pero que tanto uno como otro terminan eventualmente en un festín común como Agave propone sosteniendo la cabeza de su presa (vv. 1170ss). En este trabajo se propone que justamente entre la caza y el sacrificio está la barrera del culto que está queriendo instaurar Dioniso y que así como uno significa la subordinación de lo salvaje por el hombre y el otro la subordinación de lo humano por lo divino, al no estar claramente delimitados los agentes implicados en las dos actividades, se subvierten provocando una desgracia para la ciudad.

Así, como explica RodríGuez CidRe (2014), la caza superpone un tránsito entre el ámbito humano y el salvaje que representa un triunfo del primero sobre el segundo; en paralelo, el sacrificio representa un escenario en el cual los hombres entran en intercambio con los dioses a través de

12 Cf. RodríGuEz CidRE (2014) para una observación contraria.

13 En cambio, la sangre de la mujer virgen es apta para el sacrificio (RodRíGuez CidRE, 2014:19).

ARgos 40 (2017) ISSN 0325-4194, pp. 105-120 
los animales sacrificados, intercambio que se monta también sobre una subordinación de lo animal a lo humano y de lo salvaje a lo civilizado. En el caso de Bacantes, todo esto resulta pervertido poniendo de manifiesto la condición profana de la ciudad al no estar iniciada en los cultos báquicos, pero sobre todo pone de manifiesto que el pueblo tebano aún no ha comprendido su condición de mortal, de modo que lo salvaje todavía no ha sido del todo subyugado a la cultura. En otras palabras, la animalización hiperbólica que se identifica en la obra pone de relieve el estado salvaje que levita en la polis por el estado pre cultual de la ciudad, es por eso que el sacrificio se superpone con la caza, ya que la violencia desenfrenada aún no ha sido encauzada por la cultura al no reconocerse el hombre como tal, ubicándose correctamente en la insalvable distancia con lo divino.

Por último, cabe señalar que existe un antecedente de un ritual mal ejecutado con un desenlace igual de fatídico. Se trata del sacrificio de las vacas del Sol realizado por los compañeros de Odiseo en el canto XII de la Odisea:

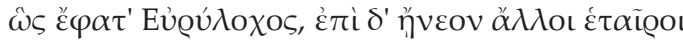

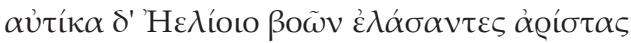

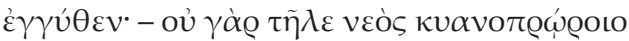

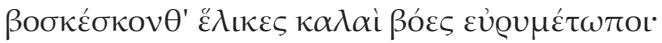

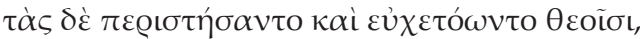

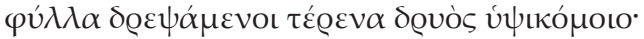

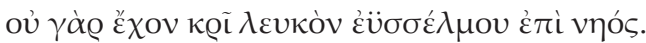

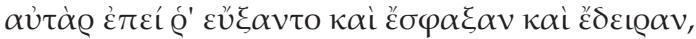

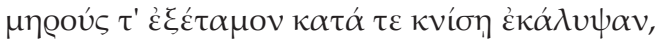

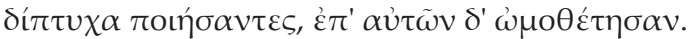

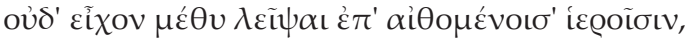

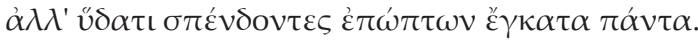

Así habló Euríloco, y los otros compañeros asentían.

En seguida, habiéndose conducido cerca de las mejores vacas

del Sol, -pues no lejos de la nave oscura

pastaban las hermosas vacas de ancha frente retorcida-,

las rodearon y hacían sus votos a los dioses,

habiendo recolectado tiernas hojas de un árbol de elevado follaje;

pues no tenían blanca harina en la nave de buena cubierta.

No obstante, enseguida rezaron, las degollaron y desollaron,

y separaron los muslos y los cubrieron con grasa por debajo,

y tras hacerlo dos veces, colocaron los trozos crudos junto a los mismos.

Y no tenían vino para libar junto a los encendidos sacrificios

pero ofrendando con agua, asaban todas las entrañas. (vv. 352-63) 
Hay por lo menos dos irregularidades en la ejecución del sacrificio. En primer lugar, no tenían harina blanca (v. 358) y, en segundo, no poseían vino para realizar las libaciones correspondientes. Se sabe que al matar las vacas del Sol los compañeros estaban rompiendo un gran juramento, lo cual implica necesariamente una especie de castigo como consecuencia. Pero además de haber violado un código de honor, no reconocieron la sacralidad de los animales, lo cual es lo mismo que no reconocer la distancia que separa al hombre de un dios.

\section{Acerca de las diferentes Bacantes}

Queda por revisar la diferencia entre las ménades tebanas y las asiáticas, para terminar de delinear la diferencia entre seguidores que han superado la barrera de lo profano y los que no, al no estar iniciados. El coro de la tragedia, compuesto por las bacantes asiáticas, después de haber sido iniciado en su culto, acompaña al dios en su recorrido por distintas ciudades en las que se va manifestando como divinidad. Ahora bien, el coro al estar formado por mujeres extranjeras cuenta con una doble alteridad frente a dos de los parámetros hegemónicos griegos que consisten básicamente en ser de género masculino y griego. No obstante, estas mujeres parecen mostrarse más acordes a los valores de la polis que las propias mujeres tebanas a la vez que proponen la experiencia de un festival de una manera controlada y benigna. En palabras de FoleY:

In contrast to the women on the mountain, the chorus, when it presents the worship of Dionysus to the city, offers the experience of festival in a benign and controlled form. The Asian women sing, dance, and presents new myths and symbols to the city; their violence is exclusively verbal (1985:237).

Por el contrario, las mujeres tebanas experimentan el rito dionisíaco en su forma más violenta, teniendo en cuenta sobre todo el desenlace funesto que les espera. Este trabajo considera que están siendo castigadas desde el comienzo, ya que el mismo Dioniso especifica en el prólogo que ellas se burlaron de Sémele siendo esta su propia hermana y, por ende, quienes menos hubieran debido (vv. 27ss).

Existe un testimonio posterior de la muerte de Penteo a manos de Ágave y sus hermanas, que puede servir como contraejemplo en cuanto a la caracterización de las mujeres de la casa real tebana. El Idilio XXVI de Teócrito relata básicamente lo mismo que la tragedia de Eurípides, pero con algunos detalles diferentes. Penteo espía a las tres mujeres mientras realizan un ritual en honor a Dioniso en el monte, es descubierto y desmembrado por sus tías y madre, también comparada con una leona, para luego 
regresar afligidas a la ciudad. Las diferencias más sobresalientes son que Penteo va por voluntad propia a espiar a las mujeres y no engañado o seducido por Dioniso, y que las mujeres están realizando el culto de manera consciente puesto que están iniciadas en los cultos dionisíacos, por lo cual saben exactamente cómo complacer al dios (vv. 3-9). Por último, se diferencia en que el poeta declara que no hay que repudiar el accionar de las mujeres, puesto que estaban actuando por voluntad del dios y nadie que desdeñe a una divinidad debe generar compasión, frente a la tragedia de Eurípides en las que "the final scenes create pity for the protagonists, raise questions about the nature of Dionysus divinity, and leave the audience confused about how to judge its dramatic experience" (Foley, 1985: 238). Este segundo testimonio da una alternativa para el sacrificio de Penteo, ya que en este caso no es un castigo para Agave y sus hermanas sino que es exclusivo para Penteo, aquel que se atreve a corromper un ritual porque no ve las marcas sagradas por su condición profana. Además, la muerte del rey en este caso sucede justamente en un recinto sagrado, puesto que las mujeres ya habían realizado doce altares (nueve para Dioniso y tres para Sémele) y estaban realizando las ofrendas requeridas a cada uno. Así, en este contraste, vemos con mayor claridad la irregularidad cultual de Agave en tanto oficiante sacrificial en Bacantes.

\section{Conclusiones}

En este trabajo se ha hecho un largo recorrido intentando demostrar que bajo el complejo y heterogéneo devenir de Bacantes se esconde un hilo conductor muy sencillo que atraviesa toda su trama. En pocas palabras, Penteo y su familia y por extensión Tebas, al no reconocer el origen divino de Dioniso tampoco ha comprendido su condición de mortal y al suceder esto, los límites entre lo divino, lo salvaje y lo humano se confunden. En consecuencia, si la caza es la subordinación de lo salvaje a lo humano, o si el sacrificio es la subordinación del humano a los dioses, al no estar claro el carácter de los agentes que llevan a cabo dichas prácticas, las mismas se subvierten y se vuelven en contra de quienes las realizan, porque ninguna de ellas puede ser dominada aún si las distancias entre uno y otro no se respetan.

Así, las mujeres tebanas, quienes en apariencia hacen un sacrificio en honor al dios, devienen en cazadoras de su propia familia. De modo que Penteo, queriendo cazar a las ménades, se convierte él mismo en victima sacrificial. En otras palabras, el mecanismo de animalización imperante señalado por la crítica (RodRIGUEz CidRE, 2012), responde al estado pre-cultual en que se encuentra Tebas.

Esto último nos lleva al primer momento de este trabajo. El prólogo consiste en un himno dedicado a Dioniso que es ejecutado por el mismo 
dios. La particularidad de este artificio anticipa el rol doble que va a ocupar Baco a lo largo de la obra, porque va a presentarse casi en su totalidad como profeta de sí mismo. De modo que entonaría desde ese lugar al prólogo, y dado el carácter inaudito de un dios celebrándose un himno a sí mismo, no se puede dejar de pensar que Dioniso está ejemplificando el modo en que una ciudad debe rendirle culto; no sólo con el himno que da inicio, sino también con los bailes forzados de las mujeres tebanas y la experimentación absolutamente violenta y descontrolada que hace Penteo del culto que niega.

En otras palabras, la tragedia parecería poner en escena la representación de un culto a modo de ejemplo o, si se quiere, la representación de un castigo ejemplar, pero, de todas maneras, evocando la propia práctica teatral. Con estas observaciones se contribuye a las lecturas ya propuestas por la crítica especializada sobre el carácter perverso del rito ejecutado y la reflexión sobre la teatralidad desplegada en la obra, pero en este trabajo ambas perspectivas de análisis se unen para explicarse y fundamentarse la una a la otra; así, en otras palabras, Dioniso, al presentarse a través de un himno dedicado a sí mismo, parece burlarse del público al ser él quien efectúa la representación cultual para los tebanos, y no la polis al dios, como correspondería.

La perversa muerte de Penteo resulta entonces no sólo un proceso de purificación de la ciudad, sino también un pasaje a un nuevo orden, puesto que este ritual no vuelve a la estructura anterior de una manera revitalizada, sino, por el contrario, se trata de que el ciudadano tebano finalmente reconozca su distancia frente al dios y, de esa manera, los límites entre lo humano, lo divino y lo salvaje se reestablezcan, y en consecuencia las prácticas propias de la civilidad sean dominadas. 


\section{Bibliografia}

Abritta, A. (2012) "Contribuciones al problema de la unidad del Himno homérico a Apolo", Argos, Vol. 35, 1, Ciudad Autónoma de Buenos Aires. Allen, T. W. (ed.) (1908) Homeri, Opera, Great Britain.

Ausfeld, K. (1903) "De Graecorum precationibus quaestiones", Jahrb, Classical Phil., 28, pp. 505ss.

Bremer, J. M. (1981) "Greek Hymns", en Versnel, H. S. (ed) Faith, Hope and Worship. Aspects of religious mentality in the Ancient World, Leiden/Brill.

BurKERT, W. (1985) Greek Religion. Archaic and Classical, Oxford, Blackwell Publishers.

Brioso SÁnchez, M. (2003) "El público del teatro griego antiguo", Teatro: Revista de Estudios Culturales, 19, pp. 9-55.

CÁssola, F. (1997) Inni Omerici. 6th ed., Milán, Fondazione Lorenzo Valla.

De Hoz, M. P. (1998) "Los himnos homéricos cortos y las plegarias cultuales", Emerita, 66, pp.49-66.

DodDs, E. R. (ed.) (1963) Euripides'Bacchae. Edited with introduction and commentary, Oxford, Clarendon Press.

Douglas, M. (1966) Purity and Danger. An analysis of the concepts of pollution and taboo, London and New York, Routledge.

Foley, H. P. (1985) Ritual irony. Poetry and sacrifice in Euripides, Cornell University Press, Ithaca and London.

Gow, A. S. F. (ed.) (1952) Theocritus, Edited with translation and commentary, Vol. I, Cambridge University Press.

IngBerg, P. (2009) Safo. Antología, Buenos Aires, Editorial Losada.

IRIARTE, A. (1996) Democracia y tragedia. La era de Pericles, Madrid.

JANKO, R. (1981) "The structure of the Homeric hymns: a study in genre", Hermes, 109, pp. 9-24.

Morand, A. F. (2001) Études sur les Hymnes orphiques, Leiden - Boston - Köln, Brill.

Nápoli, J. T. (2012) "Mito y rito dionisíaco en Bacantes de Eurípides: sobre el origen ritual del teatro", Nuntius Antiquus, UFMG, Belo Horizonte, Vol. VIII, pp. 143-150.

- - (2010) "Espectáculo y teatralidad en Bacantes de Eurípides", Humanitas, Facultad de Letras de la Universidad de Coimbra, Vol. LXII, pp. 57-81.

Patera, I. (2012) Offrir en Grèce ancienne: gestes et contextes, Stuttgart, Franz Steiner Verlag.

Pulleyn, S. (1997) Prayer in Greek Religion, Oxford, University Press. 
Rodríguez Cidre, E. (2012) "Animalizar lo masculino: Penteo en Bacantes de Eurípides”, en LóPEZ, A.; Pociña, A. \& SiLVA, M. F. (coords.) De ayer a hoy: influencias clásicas en la literatura, Coimbra, Centro de Estudos Clássicos e Humanísticos da Universidade de Coimbra.

- (2014) "Mujeres, animales y sacrificio en Bacantes de Eurípides", Asparkía, 25, pp.19-32.

Roux, J. (ed.) (1972) Euripides, Les Bacchantes, Paris, Le Belles Lettres.

SEAford, R. (ed.) (1996) Euripides, Bacchae, Warinster, Aris y Phillips.

_ (1984) "Pentheus' Vision: Bacchae 918-922", The classical Quarterly, New Series, Vol. 37, 1, pp. 76-78.

— (1981) "Dionysiac Drama and the Dionysiac Mysteries", The classical Quarterly, New Series, Vol. 31, 2, pp. 252-275.

SEgal, C. (1997) Dionysiac poetics and Euripides' Bacchae, Princeton, New Jersey Princeton University Press.

Thumiger, C. (2007) Hidden paths. Notions of self, tragic characterization and Euripides'Bacchae, Londres, Institute of Classical Studies.

Torres, D. (2015) Método filológico-didáctico para el estudio del griego clásico, Buenos Aires, Editorial de la Facultad de Filosofía y Letras de la Universidad de Buenos Aires.

Fecha de recepción: 31-08-17

Fecha de aceptación: 12-11-17 